\title{
Long-term outcome of biopsy-proven idiopathic tubulointersitial nephritis with or without uveitis in children-a nationwide follow-up study
}

\author{
Sari Rytkönen ${ }^{1,2} \cdot$ Juuso Tainio $^{3} \cdot$ Ville Saarela $^{4} \cdot$ Kira Endén $^{5} \cdot$ Janne Kataja $^{6} \cdot$ Pekka Arikoski $^{7} \cdot$ Matti Nuutinen $^{1,2}$. \\ Timo Jahnukainen ${ }^{3}$
}

Received: 6 December 2020 / Revised: 7 March 2021 / Accepted: 18 March 2021 / Published online: 18 May 2021

(C) The Author(s) 2021

\begin{abstract}
Background Only a few studies reporting the long-term outcome of children with idiopathic tubulointerstitial nephritis (TIN) and uveitis syndrome (TINU) are available. We studied the long-term kidney and ocular outcome in a nationwide cohort of children with TIN or TINU.

Methods All patients followed up for a minimum of 1 year by a paediatrician and an ophthalmologist were enrolled. The data on plasma creatinine $(\mathrm{P}-\mathrm{Cr})$, estimated glomerular filtration rate (eGFR), proteinuria, hypertension and uveitis were collected retrospectively.

Results Fifty-two patients were studied. Median age at time of diagnosis was 13.1 (1.8-16.9) years and median follow-up time was 5.7 (1.1-21.2) years. Forty-five (87\%) patients were initially treated with glucocorticoids. The median of the maximum P-Cr was $162 \mu \mathrm{mol} / \mathrm{l}(47-1,016)$ and that of eGFR $47 \mathrm{ml} / \mathrm{min} / 1.73 \mathrm{~m}^{2}(8-124)$. Uveitis was diagnosed in 33 patients $(63 \%)$ and 21 (40\%) patients developed chronic uveitis. P-Cr normalised in a median of 2 months. Eleven (21\%) patients had nephritis recurrence during or after discontinuation of glucocorticoids. At the latest follow-up, $13(25 \%)$ patients had eGFR < $90 \mathrm{ml} /$ $\mathrm{min} / 1.73 \mathrm{~m}^{2}$ (median $83 ; 61-89 \mathrm{ml} / \mathrm{min} / 1.73 \mathrm{~m}^{2}$ ). Six patients had tubular proteinuria; all presented with TIN without uveitis. Seven $(13 \%)$ patients were hypertensive. Eleven $(21 \%)$ patients had uveitis. One patient developed uraemia and was later transplanted.

Conclusions Our study questions the previously reported good long-term kidney and ocular outcome of patients with TIN/TINU. Decreased kidney function and/or ocular co-morbidities may persist for several years; thus, both kidney and ocular follow-up for at least 1 year is warranted.
\end{abstract}

Keywords TIN $\cdot$ TINU $\cdot$ Child $\cdot$ Biopsy $\cdot$ Uveitis $\cdot$ Outcome $\cdot$ Stage 5 chronic kidney disease

Timo Jahnukainen

timo.jahnukainen@hus.fi

1 Department of Children and Adolescents and PEDEGO Research Unit, Oulu University, Oulu, Finland

2 Department of Children and Adolescents, Oulu University Hospital, Oulu, Finland

3 Department of Paediatric Nephrology and Transplantation, New Children's Hospital, University of Helsinki and Helsinki University Hospital, Box 347, Stenbäckinkatu 9, 00029 Helsinki, HUS, Finland
4 Department of Ophthalmology, Oulu University Hospital, Oulu, Finland

5 Department of Paediatrics, Tampere University Hospital, Tampere, Finland

6 Department of Paediatrics and Adolescent Medicine, Turku University Hospital, Turku, Finland

7 Department of Paediatrics, University of Eastern Finland and Kuopio University Hospital, Kuopio, Finland 


\section{Introduction}

Tubulointersitial nephritis (TIN) is an inflammatory disease affecting primarily the renal interstitium and tubular wall without significant glomerular or vascular involvement [1]. TIN can sometimes be accompanied by uveal inflammation, in which case it is referred to as tubulointerstitial nephritis and uveitis (TINU syndrome). There are previous data showing that uveitis may present as a chronic and/or relapsing form of the disease [1-4].

TIN can be triggered by several causes including infections and medications, such as antibiotics, nonsteroidal antiinflammatory drugs and proton pump inhibitors, or the aetiology can be idiopathic [5]. Separately, TIN and uveitis can also be associated with systemic immunologic conditions such as sarcoidosis, systemic lupus erythematosus or inflammatory bowel disease [6-8]. TIN is a rare but significant cause of acute kidney insufficiency in children, accounting for approximately $7 \%$ of acute kidney injuries (AKI) in the paediatric population [9]. It is usually considered a condition with good long-term prognosis. However, there is evidence that some patients develop permanent kidney impairment, but studies reporting long-term outcomes of TIN/TINU syndrome in the paediatric population are scarce and follow-up times have been short $[2,4,10-12]$. Our aim was to evaluate the long-term kidney and ocular outcome in a nationwide cohort of children with idiopathic biopsy-proven TIN or TINU who were followed up by a paediatrician and an ophthalmologist according to a systematic follow-up protocol for at least 1 year.

\section{Methods}

This study was part of our previous nationwide studies and detailed patient demographics have been reported before $[3,4$, 13-15]. The study cohort was collected from all five university hospitals in Finland between 1995 and 2015. All patients with biopsy-proven TIN diagnosed before the age of 17 years were enrolled.

The diagnostic inclusion criteria of our study, whether or not the patient had uveitis, were tubulointerstitial changes found in the kidney biopsy. Criteria for kidney biopsy were typical presenting symptoms and clinical signs of TIN (Table 1), marked low molecular weight proteinuria (LMWP); either urinary alpha1-microglobulin (U- $\alpha 1-M G)$ or beta-2-microglobulin (U- $\beta 2-$ MG) and decreased eGFR. In all patients, diagnostic biopsy was performed before any immunomodulatory treatment was given. Meticulous work-up was done to exclude possible underlying conditions, such as drug-induced TIN, respiratory infection, sarcoidosis, connective tissue disorder and lymphoma. In order to find and exclude patients with secondary TIN, screening for respiratory viruses was performed by using viral serology, antigen detection and/or PCRs. Antinuclear antibodies, anti- neutrophilic cytoplasmic antibodies and tests for epidemic nephropathy (Puumala virus) were assayed. Drug-induced TIN was excluded by careful patient history. Complement components 3 and 4 and angiotensin-converting enzyme, and lysozyme concentrations were measured. In addition, sarcoidosis, connective tissue disorder and lymphomas were excluded by relevant $\mathrm{X}$-ray and laboratory tests decided individually. The differential diagnoses setup was re-evaluated if TIN recurrence occurred. Kidney biopsy samples were re-evaluated from 26 patients and the findings were scored semiquantitatively and scores for tubulointerstitial activity and chronicity indexes were calculated as follows: tubulitis $(0-3)$, interstitial inflammation $(0-3)$, tubular atrophy $(0-3)$ and interstitial fibrosis $(0-3)$. From the remaining 26 patients, the scores were collected from the pathologist statements recorded on the patient files.

A paediatric nephrologist and an ophthalmologist followed up all the patients. The follow-up protocol was comparable in all centres and included visits at least 1, 3, 6 and 12 months following the diagnosis, and at least annually thereafter if full remission was not achieved. The follow-up data were collected until June 30, 2020. Data on plasma creatinine (P-Cr), estimated GFR (eGFR), blood pressure, urine protein excretion and presence of uveitis were collected. Estimated GFR was determined according to the Schwartz formula [16]. At the follow-up visits, proteinuria was evaluated with a dipstick and in case of a positive result, with quantitative measurement of urinary albumin and low-molecular-weight (LMW) protein concentration (U- $\alpha 1-M G$ or $\beta 2-M G)$. Persisting LMWP was considered an indicator of renal tubular dysfunction. The cut-off values were $\mathrm{U}-\alpha 1-\mathrm{MG} /$ creatinine ratio $>2.2 \mathrm{mg} /$ $\mathrm{mmol}$ or U- $\beta 2-\mathrm{MG} / \mathrm{creatinine}$ ratio $>35 \mathrm{ug} / \mathrm{mmol}$. U- $\beta 2-$ MG concentration above $250 \mathrm{ug} / \mathrm{ml}$ or U- $\alpha 1-\mathrm{MG}$ concentrations above $6-12 \mathrm{mg} / \mathrm{l}$ depending on the subject's age was considered abnormal. Hypertension was stated if blood pressure was above $95^{\text {th }}$ percentile according to gender, age and height or if the patient was on antihypertensive medication [17]. Information about the medical treatment for TIN/TINU and nephritis recurrences was collected from electronic patient records. Uveitis was classified according to standardisation of uveitis nomenclature (SUN) criteria [18]. Relapsing (recurrent) uveitis was thus defined as two uveitis episodes separated by a 3-month or longer period of inactivity without treatment in between. Chronic uveitis was defined in case of relapse within $<3$ months after discontinuing treatment.

The same initial glucocorticoid treatment protocol was used at each centre [3]. Briefly, oral prednisone starting at a dose of $2 \mathrm{mg} / \mathrm{kg} /$ day (maximum $60 \mathrm{mg} / \mathrm{d}$ ) was initiated after the diagnostic biopsy was performed. In the case of full kidney function recovery, the dose was reduced after 4-week treatment to $40 \mathrm{mg} / \mathrm{m}^{2}$ every other day (eod) for 1 week and tapered in 1 -week steps by $10 \mathrm{mg} / \mathrm{m}^{2}$ eod during the next 3 
Table 1 Clinical signs and symptoms before the TIN diagnosis and the findings of the diagnostic kidney biopsy. The data are presented separately for all patients, TIN, TINU and TINU with chronic uveitis

\begin{tabular}{|c|c|c|c|c|c|c|}
\hline Feature & $\begin{array}{l}\text { All patients } \\
n=52\end{array}$ & $\begin{array}{l}\text { TIN } \\
n=19\end{array}$ & $\begin{array}{l}\text { TINU } \\
n=33\end{array}$ & $p$ value $^{\mathrm{f}}$ & $\begin{array}{l}\text { TINU with } \\
\text { chronic uveitis } \\
n=21\end{array}$ & $p$ value $^{\dagger}$ \\
\hline \multicolumn{7}{|l|}{ General symptoms } \\
\hline Fever & $39(75)$ & $15(83)$ & $24(73)$ & $0.50^{\#}$ & $16(75)$ & 0.97 \\
\hline Fatigue & $41(79)$ & $13(72)$ & $28(85)$ & $0.30^{\#}$ & $18(86)$ & $0.42^{\#}$ \\
\hline Headache & $18(35)$ & $6(33)$ & $12(36)$ & 0.40 & $9(43)$ & $0.48^{\#}$ \\
\hline Anorexia & $21(40)$ & $11(61)$ & $10(30)$ & 0.04 & $8(38)$ & 0.78 \\
\hline Arthralgia & $11(21)$ & $3(17)$ & $8(24)$ & 0.73 & $5(24)$ & $0.75^{\#}$ \\
\hline Weight loss & $24(46)$ & $8(44)$ & $16(49)$ & 0.78 & $11(52)$ & 0.58 \\
\hline Cough & $15(29)$ & $6(33)$ & $9(27)$ & 0.75 & $7(33)$ & 0.76 \\
\hline \multicolumn{7}{|l|}{ Gastrointestinal symptoms } \\
\hline Abdominal pain & $16(31)$ & $9(50)$ & $7(21)$ & 0.06 & $3(14)$ & 0.04 \\
\hline Vomiting & $9(17)$ & $6(33)$ & $3(9)$ & $0.03^{\#}$ & $2(10)$ & 0.20 \\
\hline \multicolumn{7}{|c|}{ Urinary findings and symptoms } \\
\hline Polyuria & $612)$ & $0(0)$ & $6(18)$ & $0.05^{\#}$ & $5(24)$ & $0.02^{\#}$ \\
\hline LMWP* & $50(100)$ & $19(100)$ & $31(100)$ & - & $21(100)$ & - \\
\hline Glucosuria & $48(92)$ & $17(90)$ & $31(97)^{\phi}$ & $0.28^{\#}$ & $19(95)^{*}$ & $0.83^{\#}$ \\
\hline Pyuria $(n=49)$ & $15(29)$ & $6(35)^{*}$ & $9(28)^{*}$ & 0.75 & $7(35)^{*}$ & 0.75 \\
\hline Ocular symptoms & $3(6)$ & $0(0)$ & $3(9)$ & $0.19^{\#}$ & $2(10)$ & $0.36^{\#}$ \\
\hline Dialysis & $3(6)$ & $3(16)$ & 0 & 0.04 & 0 & 0.14 \\
\hline \multicolumn{7}{|l|}{ Biopsy findings } \\
\hline Tubulitis & $1(0-3)$ & $2(0-3)$ & $1(0-2)$ & & $1(0-2)$ & 0.03 \\
\hline Interstitial inflammation & $2(0-3)$ & $2(1-3)$ & $2(0-3)$ & 0.58 & $2(1-3)$ & 0.75 \\
\hline Interstitial fibrosis gr. 1 & $10(19)$ & $3(16)$ & $7(21)$ & 0.73 & $4(19)$ & 0.98 \\
\hline Tubular atrophy gr. 1 & $14(27)$ & $6(32)$ & $8(24)$ & 0.57 & $5(24)$ & 0.68 \\
\hline
\end{tabular}

TIN, tubulointerstitial nephritis; TINU, tubulointerstitial nephritis with uveitis syndrome; chronic uveitis was defined as uveitis that had lasted more than 3 months despite treatment, with relapse within 3 months after discontinuing treatment. $L M W P$, low molecular weight proteinuria; treatment delay was defined as the time from onset of symptoms to the beginning of cortisone treatment

Percentage (range), $\chi^{2}$-test for categorical variables was used, but if one cell or more had expected count less than 5 (\#), we used Fisher's exact test and exact Sig. (2-sided)

*Data missing in 1 patient

${ }^{\phi}$ Data missing in 2 patients

$f p$ values are for differences between TIN and all TINU patients

${ }^{\dagger} p$ values are for differences between patients with chronic uveitis and all other patients (TIN and TINU without chronic uveitis) weeks. In the case of partial kidney function recovery (LMWP and/or elevated $\mathrm{P}-\mathrm{Cr}$ ) at 1 month, the prednisone dose was reduced to $1.5 \mathrm{mg} / \mathrm{kg}$ eod for a 2 -month period, after which tapered by $0.5 \mathrm{mg} / \mathrm{kg}$ eod in 1 -month steps.

Statistical analyses were performed with IBM SPSS Statistics for Macintosh, version 25. Armonk, NY: IBM Corp. We used the Mann-Whitney $U$ test to compare median values between two groups and the $\chi^{2}$ test or Fisher's exact test, as appropriate, for comparing categorical variables. Descriptive data are presented as median values and range from the lowest to the highest value. Statistical significance was defined as $p<0.05$.

\section{Results}

\section{Patient demographics and baseline data}

Altogether, 52 patients were enrolled over a 21-year study period. Twenty-nine (56\%) patients were female. Demographic data and the key laboratory findings at the time of diagnostic biopsy are presented and at the latest follow-up visit in Table 2. The median age at diagnosis was 13.1 years (range 1.8-16.9 years) and the median follow-up time was 5.7 years (range 1.1-21.2 years). Uveitis was diagnosed in 33 patients $(63 \%)$; 19 of them $(58 \%)$ were girls. In most cases, 
Table 2 Patient demographics and key laboratory findings at the time of the diagnostic kidney biopsy and the follow-up data. The data are presented separately for all patients, TIN, TINU and TINU with chronic uveitis

\begin{tabular}{|c|c|c|c|c|c|c|}
\hline & $\begin{array}{l}\text { All patients } \\
n=52\end{array}$ & $\begin{array}{l}\text { TIN } \\
n=19\end{array}$ & $\begin{array}{l}\text { TINU } \\
n=33\end{array}$ & $\begin{array}{l}p \\
\text { value }^{\mathrm{f}}\end{array}$ & $\begin{array}{l}\text { TINU with chronic } \\
\text { uveitis } \\
n=21\end{array}$ & $\begin{array}{l}p \\
\text { value }^{\dagger}\end{array}$ \\
\hline Age at diagnosis, years & $13.1(1.8-16.9)$ & $11.8(1.8-15.4)$ & $13.8(5.6-16.9)$ & 0.38 & $13.9(5.6-16.9)$ & 0.28 \\
\hline Median follow-up time, years & $5.7(1.1-21.2)$ & $5.6(1.1-15.5)$ & $4.5(1.2-21.2)$ & 0.54 & $6.1(1.9-21.2)$ & 0.06 \\
\hline Age at the latest follow-up, years & $18.4(4.5-31.5)$ & $16.7(7.7-28.8)$ & $17.9(4.5-31.5)$ & 0.21 & $18.5(11.3-31.5)$ & 0.03 \\
\hline \multicolumn{7}{|l|}{ Initial data } \\
\hline $\mathrm{CRP}, \mathrm{mg} / \mathrm{l}(n=41)$ & $50(3-224)$ & $50(3-224)^{*}$ & $43(3-135)^{\#}$ & 0.80 & $33(3-110)^{\#}$ & 0.77 \\
\hline $\mathrm{ESR}, \mathrm{mm} / \mathrm{h}$ & $94(9-140)$ & $102(64-128)^{*}$ & $86(9-128)$ & 0.68 & $79(14-128)$ & 0.07 \\
\hline $\mathrm{P}-\mathrm{Cr}, \mu \mathrm{mol} / 1$ & $162(47-1016)$ & $234(64-1016)$ & $139(47-416)$ & 0.01 & $169(47-416)$ & 0.24 \\
\hline P-Urea, mmol/1 $(n=49)$ & $9.0(4.4-32.7)$ & $10.8(5.5-32.7)$ & $7.9(4.4-18.3)$ & 0.04 & $8.5(4.7-16.8)$ & 0.28 \\
\hline U- $\alpha \mathrm{l}-\mathrm{MG} \mathrm{mg/l}(n=14)$ & $80(11-246)$ & $141(75-246)$ & $78(11-137)$ & 0.40 & $76(11-137)$ & 0.52 \\
\hline $\mathrm{U}-\beta 2-\mathrm{MG} \mu \mathrm{g} / \mathrm{l}(n=36)$ & $\begin{array}{l}24250 \\
\quad(1600-120000)\end{array}$ & $\begin{array}{l}23438 \\
\quad(2090-12000)\end{array}$ & $\begin{array}{l}24800 \\
\quad(1600-110200)\end{array}$ & 0.64 & $34000(1600-110200)$ & 0.33 \\
\hline Haemoglobin, g/L & $103(85-129)$ & $99(85-126)$ & $104(86-129)$ & 0.14 & $104(94-129)$ & 0.30 \\
\hline WBC, $\mathrm{E}^{9} / \mathrm{L}(n=39)$ & $8.9(4.3-31.0)$ & $8.4(5.9-31.0)$ & $8.9(4.3-12.9)$ & 0.76 & $8.8(4.3-12.9)$ & 0.63 \\
\hline B-Eosinophiles, $\mathrm{E}^{9} / 1(n=39)$ & $0.31(0-0.96)$ & $0.31(0-0.71)$ & $0.31(0-0.96)$ & 0.90 & $0.35(0-0.84)$ & 0.67 \\
\hline $\mathrm{P}-\mathrm{Pi}, \mathrm{mmol} / \mathrm{l}(n=33)$ & $1.09(0.68-2.27)$ & $0.98(0.78-2.27)$ & $1.11(0.68-1.46)$ & 0.35 & $1.09(0.68-1.46)$ & 0.80 \\
\hline \multicolumn{7}{|l|}{ Follow-up data } \\
\hline $\mathrm{P}-\mathrm{Cr}, \mu \mathrm{mol} / \mathrm{l}$ & $72(37-112)$ & $64(37-111)$ & $74(50-112)$ & 0.52 & $76(50-112)$ & 0.28 \\
\hline $\mathrm{eGFR}, \mathrm{ml} / \mathrm{min} / 1.73 \mathrm{~m}^{2}$ & $106(61-183)$ & $117(61-183)$ & $106(68-158)$ & 0.64 & $109(68-158)$ & 0.68 \\
\hline $\mathrm{eGFR}<90 \mathrm{ml} / \mathrm{min} / 1.73 \mathrm{~m}^{2}, n(\%)$ & $13(25)$ & $5(28)$ & $8(24)$ & 0.78 & $5(24)$ & 0.82 \\
\hline CKD $5^{*}, n(\%)$ & $1(2)$ & $1(6)$ & 0 & - & 0 & - \\
\hline Elevated blood pressure, $n(\%)$ & $7(13)$ & $2(11)$ & $5(15)$ & 0.69 & $3(14)$ & 0.92 \\
\hline LMWP $n(\%)$ & $6(12)$ & $6(33)$ & $0(0)$ & - & $0(0)$ & - \\
\hline Nephritic relapse & $12(23)$ & $5(26)$ & $7(21)$ & 0.67 & $6(29)$ & 0.44 \\
\hline
\end{tabular}

$T I N$, tubulointerstitial nephritis; TINU, tubulointerstitial nephritis with uveitis syndrome; chronic uveitis was defined as uveitis lasting more than 3 months despite treatment and/or with relapse within 3 months after discontinuing treatment. $C R P$, C-reactive protein; $E S R$, erythrocyte sedimentation rate; $P$ - $C r$, plasma creatinine concentration; $e G F R$, estimated glomerular filtration rate; $U-\alpha 1-M G$, urine alpha-1-microglobulin concentration (normal value $<15 \mathrm{mg} / \mathrm{l}$ ); U- $\beta 2-M G$, urine beta-2-microglobulin concentration (normal value $<250 \mu \mathrm{g} / \mathrm{l}$ ); $W B C$, white blood cells; $P$ - $P i$, plasma phosphate concentration; $C K D 5$, stage 5 chronic kidney disease; reported values are median values with range in brackets. For continuous variables, the nonparametric Mann-Whitney $U$ test was used. A two-tailed $p$ value is reported

*TIN $n=13$ for CRP and $n=17$ for ESR

\#TINU $n=28$ and $n=19$ in TINU with chronic uveitis group

$f$ Median values were compared between TIN and TINU patients

$\dagger$ Median values were compared between patients with chronic uveitis and all other patients (TIN and TINU without chronic uveitis)

uveitis was diagnosed at the same time with TIN, but in four (12\%) patients, uveitis appeared 3-10 months after TIN. Twenty-one of the 33 uveitis patients (40\%) developed chronic uveitis.

Fever, fatigue and weight loss were among the most common presenting symptoms in all patient groups (Table 1). Gastrointestinal symptoms, anorexia (61\%), abdominal pain (50\%) and vomiting (33\%) were common as presenting clinical symptoms especially in TIN patients (Table 1). At the time of diagnosis, the median peak P-Cr was $162 \mu \mathrm{mol} / 1$ (range 47-1016) and eGFR $47 \mathrm{ml} / \mathrm{min}$ (8-124). Plasma phosphate (P-Pi) concentration was below the lower limit normal in $55 \%$ of the patients. In an additional five patients, P-Pi was within normal range at presentation, but decreased to hypophosphatemia after resolution of acute kidney injury. There was no difference in P-Pi concentrations between TIN and TINU patients (Table 2). Urinary Pi concentrations were not measured routinely. All patients presented with LMWP and the vast majority had glucosuria at the time of diagnosis. Pyuria was found in $16(31 \%)$ of the patients. Eosinophils were not systematically investigated in urine samples (Table 1). The initial P-Cr was higher in the patients with isolated nephritis $(234 \mu \mathrm{mol} / \mathrm{l})$ than in the patients with TINU syndrome $(139 \mu \mathrm{mol} / \mathrm{l} ; p=0.007)$ and eGFR was correspondingly lower in TIN patients $(35 \mathrm{ml} / \mathrm{min})$ than in patients with TINU (59 ml/min, $p=0.008$ ) (Table 2). Patients 
with isolated TIN required dialysis more often than those diagnosed with concomitant uveitis ( $15.8 \%$ versus $0 \%, p=0.04$, respectively). The tubulitis score in the diagnostic kidney biopsy was significantly higher in TIN patients than in TINU patients $(p=0.001)$ or in patients with chronic uveitis $(p=$ 0.03 ) (Table 1).

Forty-five $(87 \%)$ of the patients were initially treated with prednisone. The median duration of therapy was $6(0.1-66.0)$ months. In TINU patients, the treatment time was significantly shorter than in patients with TIN or chronic uveitis (Table 3).

\section{Kidney outcome}

At the latest follow-up visit, the median P-Cr was $72 \mu \mathrm{mol} / 1$ (37-112) and median eGFR $106 \mathrm{ml} / \mathrm{min} / 1.73 \mathrm{~m}^{2}$ (61-183) (Table 2). Thirteen patients $(25 \%)$ had eGFR $<90 \mathrm{ml} / \mathrm{min} /$ $1.73 \mathrm{~m}^{2}$ (median $83 \mathrm{ml} / \mathrm{min} / 1.73 \mathrm{~m}^{2}(61-89)$ ) but none of those had eGFR $<60 \mathrm{ml} / \mathrm{min} / 1.73 \mathrm{~m}^{2}$. One additional patient underwent kidney transplantation 10 years after the TIN diagnosis. At the time of diagnosis, the median P-Cr tended to be higher in the patients with later reduced eGFR when compared to those with eGFR $>90 \mathrm{ml} / \mathrm{min} / 1.73 \mathrm{~m}^{2}$ at the last follow-up; however, the difference did not reach statistical significance (Table 4). The initial laboratory findings and biopsy scores were compared between the two groups and the only significant difference was higher interstitial inflammation score $(p=0.04)$ among patients with eGFR $>90 \mathrm{ml} /$ $\mathrm{min} / 1.73 \mathrm{~m}^{2}$ at the latest follow-up visit (Table 4).

In our TIN/TINU cohort, P-Cr normalised at a median of 2 (1-36) months. In patients with final eGFR $<90 \mathrm{ml} / \mathrm{min} / 1.73$ $\mathrm{m}^{2}$, the median time to normal P-Cr was 2.5 months, which was significantly longer $(p=0.02)$ than in those with normal eGFR at the latest follow-up visit (Table 4). There was no statistically significant difference in the $\mathrm{P}-\mathrm{Cr}$ normalisation rate between the patients with or without uveitis (Table 3). However, in patients with chronic uveitis, the normalisation time of P-Cr (median of two months; range 0-36 months) was statistically significantly $(p=0.021)$ longer than in TINU patients (1 month; range 0-3 months). Eleven patients had nephritis recurrence, defined as elevated $\mathrm{P}-\mathrm{Cr}$ and increased urinary microglobulin excretion, during prednisone weaning. Recurrence was found in five TIN patients and five patients with chronic uveitis and in only one TINU patient. However, the recurrence rate did not differ statistically significantly between the groups (Table 3). Four patients with poor treatment response underwent a second biopsy due to prolonged nephritis symptoms. One patient was diagnosed with sarcoidosis and since excluded from the study. Two patients finally achieved remission. One patient did not achieve renal remission with glucocorticoid treatment and received additional azathioprine and cyclosporine A therapy for persistent TIN. He was still on cyclosporine monotherapy during his latest follow-up visit at the age of 22 years.

At the latest follow-up visit, only one patient had mild proteinuria $(1+$ in dipstick) in urine analysis. Urinary LMW protein excretion was elevated in 6 out of 36 patients analysed (17\%); all six cases among the 18 TIN patients presenting without uveitis. Seven (13\%) patients had elevated blood pressure and five $(10 \%)$ were on antihypertensive medication. Four $(57 \%)$ of these seven hypertensive patients had tubular atrophy and/or interstitial fibrosis in their diagnostic kidney biopsy, suggesting chronic changes. Two patients had high plasma renin concentration but no evidence of renal arterial stenosis. We did not find any statistically significant differences in eGFR, P-Cr or in the occurrence of hypertension in patients with or without uveitis at the latest follow-up visit.

\section{Ocular outcome}

Eleven patients (21\%) had uveitis at the latest follow-up visit (Table 1). Eight patients were on topical prednisone treatment at the latest follow-up. Two of them also had methotrexate
Table 3 The treatment delay, frequency, length and efficiency of the glucocorticoid therapy and the number of nephritis relapses. The data are presented separately for patients with isolated tubulointerstitial nephritis, patients with uveitis and chronic uveitis

\begin{tabular}{lllll}
\hline & TIN & TINU \\
$n=19$ & $n=12$ & $\begin{array}{l}\text { TINU with chronic uveitis } \\
n=21\end{array}$ & $p$ value \\
\hline Corticosteroid therapy, $n(\%)$ & $18(100)$ & $10(83)$ & $17(81)$ & 0.15 \\
Treatment delay, days & $31(11-173)$ & $41(13-190)$ & $38(18-190)^{*}$ & 0.16 \\
Duration of medication, months & $7.5(2-24)$ & $2(0.1-12)$ & $6.5(2-66) n=15$ & 0.01 \\
Time to normal creatinine, months & $1(1-12)^{*}$ & $1(0-3)^{\#}$ & $2(0-36)$ & 0.06 \\
Time to normal ESR, months & $2(1-6) n=16$ & $1(0-6)^{\#}$ & $1(0-11)$ & 0.67 \\
Nephritis relapse, $n(\%)$ & $5(26)$ & $1(8)$ & $6(29)^{*}$ & 0.40 \\
\hline
\end{tabular}

Data is presented as $n(\%)$ or median (range). Analyses performed by Chi-squared or Kruskal-Wallis test, as appropriate. A two-tailed $p$ value is reported. Treatment delay was defined as the time from onset of symptoms to the beginning of cortisone treatment. ESR, erythrocyte sedimentation rate

*Missing two cases; \# missing one case 
Table 4 The key laboratory findings at the time of the diagnostic biopsy, clinical parameters and corticosteroid treatment time according to glomerular filtration rate below and above $90 \mathrm{ml} / \mathrm{min} / 1.73 \mathrm{~m}^{2}$ at the latest follow-up

\begin{tabular}{|c|c|c|c|}
\hline & $\begin{array}{l}\mathrm{eGFR}<90 \mathrm{ml} / \mathrm{min} / 1.73 \mathrm{~m}^{2} \\
n=14\end{array}$ & $\begin{array}{l}\mathrm{eGFR}>90 \mathrm{ml} / \mathrm{min} / 1.73 \mathrm{~m}^{2} \\
n=38\end{array}$ & $p$ value \\
\hline Age at diagnosis, years & $13.8(5.6-16.0)$ & $12.6(1.8-16.9)$ & 0.10 \\
\hline $\mathrm{P}-\mathrm{Cr}$ at diagnosis, $\mu \mathrm{mol} / 1$ & $192(74-844)$ & $153(47-1016)$ & 0.32 \\
\hline eGFR at diagnosis, $\mathrm{ml} / \mathrm{min} / 1.73 \mathrm{~m}^{2}$ & $55(13-95)$ & $46(8-124)$ & 0.81 \\
\hline ESR at diagnosis, $\mathrm{mm} / \mathrm{h}$ & $95(17-114),(n=10)$ & $94(9-140),(n=35)$ & 0.56 \\
\hline Haemoglobin, g/1 & $107(86-126)$ & $99(85-129)$ & 0.45 \\
\hline WBC, $\mathrm{E}^{9} / 1(n=39)$ & $7.6(5.9-10.6)$ & $8.9(4.3-31.0)$ & 0.20 \\
\hline Eosinophiles, $\mathrm{E}^{9} / 1(n=39)$ & $0.27(0.06-0.54)$ & $0.33(0-0.69)$ & 0.38 \\
\hline $\mathrm{P}-\mathrm{Pi}, \mathrm{mmol} / \mathrm{l}(n=33)$ & $0.85(0.68-1.49)$ & $1.10(0.78-2.27)$ & 0.15 \\
\hline P-Urea, mmol/1 $(n=49)$ & $7.1(4.4-24.8)$ & $9.5(4.7-32.7)$ & 0.19 \\
\hline Glucosuria $(n=51)$ & $13(100)$ & $35(92)$ & 0.30 \\
\hline Pyuria $(n=50)$ & $3(23)$ & $13(35)$ & 0.43 \\
\hline Dialysis & 0 & $3(8)$ & 0.28 \\
\hline TINU (\%) & $8(57)$ & $25(64)$ & 0.75 \\
\hline Chronic uveitis, $n(\%)$ & $5(33)$ & $16(42)$ & 0.76 \\
\hline Treatment delay, days & $44(16-190)$ & $35(11-173)$ & 0.67 \\
\hline Corticosteroid therapy, $n(\%)$ & $13(100)$ & $33(85)$ & 0.12 \\
\hline Duration of medication, months & $9.5(0.1-15)$ & $6(1-48)$ & 0.49 \\
\hline Time to normal creatinine, months & $2.5(1-14)$ & $1(0-36)$ & 0.02 \\
\hline Nephritis relapse, $n(\%)$ & $3(23)$ & $9(21)$ & 0.87 \\
\hline Interstitial inflammation & $1(0-3)$ & $2(1-3)$ & 0.04 \\
\hline Interstitial fibrosis gr. 1 & $3(21)$ & $7(18)$ & 0.81 \\
\hline Tubular atrophy gr. 1 & $4(29)$ & $10(26)$ & 0.87 \\
\hline
\end{tabular}

Data presented as $n(\%)$ or median (range) and analyses performed by Chi-squared or Kruskal-Wallis test, as appropriate. Two-tailed $p$ value is reported. Number of subjects within group presented if missing cases. $P$ - $C r$, plasma creatinine; $e G F R$, estimated glomerular filtration rate; $E S R$, erythrocyte sedimentation rate; $W B C$, white blood cells; $P-P i$, plasma phosphate concentration; $T I N U$, tubulointerstitial nephritis and uveitis; treatment delay was defined as the time from onset of symptoms to the beginning of cortisone treatment treatment. One additional patient was on methotrexate monotherapy, and one had mycophenolate mofetil and adalimumab treatments for persistent uveitis.

One patient presented severe treatment-resistant uveitis. She was diagnosed with uveitis concomitantly with TIN. Her eGFR was $22 \mathrm{ml} / \mathrm{min} / 1.73 \mathrm{~m}^{2}$ at the time of diagnosis. She was initially treated with intravenous methylprednisone pulses followed by oral prednisone, cyclosporine A, mycophenolate mofetil, infliximab and finally, adalimumab before ocular remission was achieved. Her eGFR was $112 \mathrm{ml} / \mathrm{min} /$ $1.73 \mathrm{~m}^{2}$ at the last follow-up visit.

The initial laboratory parameters and biopsy findings did not differ significantly between those patients with chronic/ recurrent uveitis and the others. The only exception was the tubulitis score in diagnostic kidney biopsy, which was higher in patients without chronic uveitis (Table 1).

\section{Discussion}

To our knowledge, the present study describes the largest (52 children) cohort of biopsy-proven paediatric TIN patients with the longest follow-up time (5.7 years) reported in the literature $[1,2,10,11,19,20]$. Unlike other studies, we only included patients with idiopathic TIN. Adult TIN follow-up cohorts are also few and small in size, and they also contain other than idiopathic TIN patients [21-23].

Our results question the general supposition that the outcome of paediatric patients with idiopathic TIN is generally good $[2,4,12]$, since $25 \%$ of the patients had CKD stage 2 (eGFR $60-89 \mathrm{ml} / \mathrm{min} / 1.73 \mathrm{~m}^{2}$ ) and one patient $(2 \%)$ had developed stage 5 chronic kidney disease at the latest follow-up visit. Neither was the ocular outcome optimal, since uveitis was diagnosed in $63 \%$ of the patients and $21 \%$ of all studied patients had active uveitis after a median 68 months followup, which further highlights the importance of ocular followup in this patient group. LMWP was found in $17 \%$ of the patients; interestingly, all cases were among those with isolated TIN without uveitis. Unfortunately, we could not identify any clinical parameters or biopsy findings in our cohort which would predict long-term kidney outcome.

TIN is known to account for up to $25 \%$ of AKIs in the adult population and 5-7\% in children [9, 24, 25]. Data regarding long-term kidney outcomes are scarce. In the adult population, 
subnormal kidney function was found in $50 \%$ of the TIN patients 18 months after the diagnosis [25]. In a recent study by Howell et al. [2], $60 \%$ of the paediatric patients with TIN had eGFR below $80 \mathrm{ml} / \mathrm{min} / 1.73 \mathrm{~m}^{2}$ after 21 months followup. In the present study, kidney function was classified according to the KDIGO CKD categories. One-quarter of this cohort had eGFR $<90 \mathrm{ml} / \mathrm{min} / 1.73 \mathrm{~m}^{2}$ at their latest follow-up visit. In $16 \%$ of the patients, eGFR was below $80 \mathrm{ml} / \mathrm{min} / 1.73$ $\mathrm{m}^{2}$. This is in accordance with our previous study reporting declined eGFR in $4 / 26$ (15\%) of the patients, the follow-up time being 33 months [4]. The better kidney outcome in our study may be explained by a longer follow-up time. In the present study, the median time to P-Cr normalisation was 2 months; however, the range was up to 36 months, suggesting that late recovery of kidney function is possible. This is also supported by Clarkson et al. in their study in an adult TIN population [24].

The role of glucocorticoid treatment in kidney outcome has remained unclear. There are some studies suggesting a favourable effect of prednisone treatment on kidney function in adults with drug-induced TIN [24, 25]. Our previous small prospective study suggested that prednisone accelerated kidney recovery in paediatric patients with idiopathic TIN; however, there was no significant difference in GFR 6 months after the diagnosis [26]. The present study is not able to clarify this issue, since 45 of the 52 patients $(87 \%)$ had received prednisone treatment. However, it appears that prednisone has had a favourable effect on TIN, since nephritis relapse was found in 11 patients $(21 \%)$ during prednisone weaning. It is also noticeable that the treatment time in patients with isolated TIN and patients with chronic TINU did not differ, suggesting that long-lasting oral glucocorticoid treatment was not entirely due to chronic uveitis.

Uveitis appears to be more frequent among paediatric TIN patients than in adults $[2,4,27]$. In the present study, $63 \%$ of the patients had TINU, which is in accordance with the findings by Howell et al. and Roy et al. [2, 11]. According to the literature, in about half of the cases uveitis was diagnosed without any ocular symptoms and simultaneously with TIN [2-4]. In our present cohort, $8 \%$ of uveitis cases were diagnosed several months after the occurrence of nephritis despite normal initial ocular findings. It is also important to note that $40 \%$ of our patients developed chronic uveitis and in $21 \%$, uveitis was still active at the latest follow-up visit after a median of 6.1 years (range 1.9-21.2). The risk of persisting uveitis should be taken into account especially after weaning off glucocorticoids. In our current protocol, all paediatric patients with idiopathic TIN visit an ophthalmologist at the time of TIN diagnosis and three monthly for at least 1 year.

The pathomechanisms behind TIN have remained unclear. There are data suggesting that it is an autoimmune disorder with susceptibility to becoming chronic $[14,15]$. In previous studies, we and others have shown that there are associations between certain human leukocyte antigen types [13, 28, 29], genetic variations in the inflammatory mediators [15], and that regulatory $\mathrm{T}$ cell function is altered [14] in patients with TIN/TINU syndrome and chronic uveitis, which may suggest autoimmune origin. This could, at least theoretically, increase the risk for chronic kidney dysfunction and kidney failure; however, there is some evidence that patients with the worst kidney outcome have had some other additional condition of autoimmune origin, such as sarcoidosis or inflammatory bowel disease [30-32]. Interestingly, in the present cohort, patients with isolated nephritis had significantly higher $\mathrm{P}-\mathrm{Cr}$ at the time of the diagnostic biopsy. In addition, LMWP was identified at the latest follow-up visit in TIN patients only. On the other hand, there was no difference in the final eGFR between the patients with isolated TIN and TINU syndrome. The definite diagnosis of TIN is based on kidney biopsy and it is possible that, as in many other conditions, there are different conditions behind similar histological findings. This may in some cases lead to variation in the long-term kidney outcome.

Our study has some weaknesses. As in all retrospective studies, the available data are limited in the present study. However, in Finland, we have developed a uniform followup protocol for TIN/TINU patients. Therefore, the frequency and length of follow-up are quite similar in all paediatric nephrology centres in Finland. Another caveat is the relatively limited number of study subjects. However, TIN is a rare disease in the paediatric population and there are no previous paediatric data with a cohort this large $(n=52)$ and follow-up time this long (5.7 years), which can be considered a strength of our study.

In conclusion, we and others have previously shown that in most patients with acute idiopathic TIN, the recovery of kidney function is good. However, our study questions the good long-term kidney and ocular outcome of the patients with TIN/TINU. Decreased kidney function and/or ocular comorbidities may persist for several years, and both kidney and ocular follow-up for at least 1 year is therefore warranted.

Supplementary Information The online version contains supplementary material available at https://doi.org/10.1007/s00467-021-05060-5.

Author contribution SR, MN and TJ designed the study. All authors recruited study patients and collected clinical data. SR, JT, VS, MN and TJ performed data analysis. All authors interpreted data. SR and TJ drafted the first version of the manuscript and all authors participated in revising the manuscript. All authors approved the final manuscript.

Funding Open access funding provided by University of Helsinki including Helsinki University Central Hospital. This work was supported by a grant to SR and TJ from the Foundation for Paediatric Research, the Päivikki and Sakari Sohlberg Foundation, and the Alma and K.A. Snellman Foundation, Oulu, Finland. 
Data availability The datasets generated during and/or analysed during the current study are available from the corresponding author on reasonable request.

\section{Declarations}

Ethics approval All procedures performed in studies involving human participants were in accordance with the ethical standards of the institutional and/or national research committee and with the 1964 Helsinki declaration and its later amendments or comparable ethical standards. The study was approved by the ethics committee of Helsinki University Hospital.

Consent to participate Written informed consent was obtained from all participants (and their guardians if necessary).

Competing interests The authors declare no competing interests.

Open Access This article is licensed under a Creative Commons Attribution 4.0 International License, which permits use, sharing, adaptation, distribution and reproduction in any medium or format, as long as you give appropriate credit to the original author(s) and the source, provide a link to the Creative Commons licence, and indicate if changes were made. The images or other third party material in this article are included in the article's Creative Commons licence, unless indicated otherwise in a credit line to the material. If material is not included in the article's Creative Commons licence and your intended use is not permitted by statutory regulation or exceeds the permitted use, you will need to obtain permission directly from the copyright holder. To view a copy of this licence, visit http://creativecommons.org/licenses/by/4.0/.

\section{References}

1. Takemura T, Okada M, Hino S, Fukushima K, Yamamoto S, Miyazato H, Maruyama K, Yoshioka K (1999) Course and outcome of tubulointerstitial nephritis and uveitis syndrome. Am J Kidney Dis 34:1016-1021. https://doi.org/10.1016/S02726386(99)70006-5

2. Howell M, Sebire NJ, Marks SD, Tullus K (2016) Biopsy-proven paediatric tubulointerstitial nephritis. Pediatr Nephrol 31:16251630. https://doi.org/10.1007/s00467-016-3374-9

3. Saarela V, Nuutinen M, Ala-Houhala M, Arikoski P, Rönnholm K, Jahnukainen T (2013) Tubulointerstitial nephritis and uveitis syndrome in children: a prospective multicenter study. Ophthalmology 120:1476-1481. https://doi.org/10.1016/j.ophtha.2012.12.039

4. Jahnukainen T, Ala-Houhala M, Karikoski R, Kataja J, Saarela V, Nuutinen M (2011) Clinical outcome and occurrence of uveitis in children with idiopathic tubulointerstitial nephritis. Pediatr Nephrol 26:291-299. https://doi.org/10.1007/s00467-010-1698-4

5. Praga M, Sevillano A, Auñón P, González E (2015) Changes in the aetiology, clinical presentation and management of acute interstitial nephritis, an increasingly common cause of acute kidney injury. Nephrol Dial Transplant 30:1472-1479. https://doi.org/10.1093/ ndt/gfu326

6. Pagni F, Galimberti S, Galbiati E, Rebora P, Pietropaolo V, Pieruzzi F, Smith AJ, Ferrario F (2015) Tubulointerstitial lesions in lupus nephritis: International multicentre study in a large cohort of patients with repeat biopsy. Nephrology (Carlton) 21:35-45. https:// doi.org/10.1111/nep.12555

7. Coutant R, Leroy B, Niaudet P, Loirat C, Dommergues JP, André JL, Baculard A, Bensman A (1999) Renal granulomatous sarcoidosis in childhood: a report of 11 cases and a review of the literature.
Eur J Pediatr 158:154-159. https://doi.org/10.1007/ s004310051038

8. Oikonomou K, Kapsoritakis A, Eleftheriadis T, Stefanidis I, Potamianos S (2011) Renal manifestations and complications of inflammatory bowel disease. Inflamm Bowel Dis 17:1034-1045. https://doi.org/10.1002/ibd.21468

9. Ellis D, Fried WA, Yunis EJ, Blau EB (1981) Acute interstitial nephritis in children: a report of 13 cases and review of the literature. Pediatrics 67:862-870

10. Clavé S, Rousset-Rouvière C, Daniel L, Tsimaratos M (2019) Acute tubulointerstitial nephritis in children and chronic kidney disease. Arch Pediatr 26:290-294. https://doi.org/10.1016/j. arcped.2019.05.002

11. Roy S, Awogbemi T, Holt RCL (2020) Acute tubulointerstitial nephritis in children- a retrospective case series in a UK tertiary paediatric centre. BMC Nephrol 21:17. https://doi.org/10.1186/ s12882-020-1681-7

12. Vohra S, Eddy A, Levin AV, Taylor G, Laxer RM (1999) Tubulointerstitial nephritis and uveitis in children and adolescents. Four new cases and a review of the literature. Pediatr Nephrol 13: 426-432. https://doi.org/10.1007/s004670050634

13. Peräsaari J, Saarela V, Nikkilä J, Ala-Houhala M, Arikoski P, Kataja J, Rönnholm K, Merenmies J, Nuutinen M, Jahnukainen T (2013) HLA associations with tubulointerstitial nephritis with or without uveitis in Finnish pediatric population: a nation-wide study. Tissue Antigens 81:435-441. https://doi.org/10.1111/tan.12116

14. Rytkönen SH, Kulmala P, Autio-Harmainen H, Arikoski P, Endén K, Kataja J, Karttunen T, Nuutinen M, Jahnukainen T (2018) FOXP3 $+\mathrm{T}$ cells are present in kidney biopsy samples in children with tubulointerstitial nephritis and uveitis syndrome. Pediatr Nephrol 33:287-293. https://doi.org/10.1007/s00467-017-3796-z

15. Rytkönen S, Ritari J, Peräsaari J, Saarela V, Nuutinen M, Jahnukainen T (2019) IL-10 polymorphisms +434T/C, +504G/T, and $-2849 \mathrm{C} / \mathrm{T}$ may predispose to tubulointersititial nephritis and uveitis in pediatric population. PLoS One 14:e0211915. https:// doi.org/10.1371/journal.pone.0211915

16. Schwartz GJ, Brion LP, Spitzer A (1987) The use of plasma creatinine concentration for estimating glomerular filtration rate in infants, children, and adolescents. Pediatr Clin N Am 34:571-590. https://doi.org/10.1016/s0031-3955(16)36251-4

17. Flynn JT, Kaelber DC, Baker-Smith CM, Blowey D, Carroll AE, Daniels SR, de Ferranti SD, Dionne JM, Falkner B, Flinn SK, Gidding SS, Goodwin C, Leu MG, Powers ME, Rea C, Samuels J, Simasek M, Thaker VV, Urbina EM; SUBCOMMITTEE ON SCREENING AND MANAGEMENT OF HIGH BLOOD PRESSURE IN CHILDREN (2017) Clinical practice guideline for screening and management of high blood pressure in children and adolescents. Pediatrics 140:e20171904. https://doi.org/10. 1542/peds.2017-1904

18. Douglas A, Jabs DA, Nussenblatt RB, Rosenbaum JT; Standardization of Uveitis Nomenclature (SUN) Working Group (2005) Standardization of uveitis nomenclature for reporting clinical data: results of the First International Workshop. Am J Ophthalmol 140:509-516. https://doi.org/10.1016/j.ajo.2005.03. 057

19. Sobolewska B, Bayyoud T, Deuter C, Doycheva D, Zierhut M (2018) Long-term follow-up of patients with Tubulointerstitial Nephritis and Uveitis (TINU) syndrome. Ocul Immunol Inflamm 26:601-607. https://doi.org/10.1080/09273948.2016.1247872

20. Kobayashi Y, Honda M, Yoshikawa N, Ito H (2000) Acute tubulointerstitial nephritis in 21 Japanese children. Clin Nephrol 54:191-197

21. Sanchez-Burson J, Garcia-Porrua C, Montero-Granados R, Gonzalez-Escribano F, Gonzalez-Gay MA (2002) Tubulointerstitial nephritis and uveitis syndrome in Southern 
Spain. Semin Arthritis Rheum 32:125-129. https://doi.org/10. 1053/sarh.2002.33718

22. Sobolewska B, Bayyoud T, Deuter C, Doycheva D, Zierhut M (2016) Long-term follow-up of patients with Tubulointerstitial Nephritis and Uveitis (TINU) syndrome. Ocul Immunol Inflamm 26:601-607. https://doi.org/10.1080/09273948.2016.1247872

23. Li C, Su T, Chu R, Li X, Yang L (2014) Tubulointerstitial nephritis with uveitis in Chinese adults. Clin J Am Soc Nephrol 9:21-28. https://doi.org/10.2215/CJN.02540313

24. Clarkson MR, Giblin L, O'Connell FP, O'Kelly P, Walshe JJ, Conlon P, O'Meara Y, Dormon A, Campbell E, Donohoe J (2004) Acute interstitial nephritis: clinical features and response to corticosteroid therapy. Nephrol Dial Transplant 19:2778-2783. https://doi.org/10.1093/ndt/gfh485

25. Gonzáles E, Gutiérrez E, Galeano C, Chevia C, de Sequera P, Bernis C, Parra EG, Delgado R, Sanz M, Ortiz M, Goicoechea M, Quereda C, Olea T, Bouarich H, Hernández Y, Segovia B, Praga M (2008) Early steroid treatment improves the recovery of renal function in patients with drug-induced acute interstitial nephritis. Kidney Int 73:940-946. https://doi.org/10.1038/sj.ki. 5002776

26. Jahnukainen T, Saarela V, Arikoski P, Ylinen E, Rönnholm K, AlaHouhala M, Nuutinen M (2013) Prednisone in the treatment of tubulointerstitial nephritis in children. Pediatr Nephrol 28:12531260. https://doi.org/10.1007/s00467-013-2476-x

27. Mandeville JT, Levinson RD, Holland GN (2001) The tubulointerstitial nephritis and uveitis syndrome. Surv Ophthalmol 46:195-208. https://doi.org/10.1016/S0039-6257(01) 00261-2
28. Reddy AK, Hwang YS, Mandelcorn ED, Davis JL (2014) HLADR, DQ class II DNA typing in pediatric panuveitis and tubulointerstitial nephritis and uveitis. Am J Ophthalmol 157: 678-686. https://doi.org/10.1016/j.ajo.2013.12.006

29. Levinson RD, Park MS, Rikkers SM, Reed EF, Smith JR, Martin TM, Rosenbaum JT, Foster CS, Sherman MD, Holland GN (2003) Strong associations between specific HLA-DQ and HLA-DR alleles and the tubulointerstitial nephritis and uveitis syndrome. Invest Ophthalmol Vis Sci 44:653-657. https://doi.org/10.1167/ iovs.02-0376

30. Marcus SB, Brown JB, Melin-Aldana H, Strople JA (2008) Tubulointerstitial nephritis: an extraintestinal manifestation of Crohn disease in children. J Pediatr Gastroenterol Nutr 46:338341. https://doi.org/10.1097/MPG.0b013e31806dc2c4

31. Waters AM, Zachos M, Herzenberg AM, Harvey E, Rosenblum ND (2008) Tubulointerstitial nephritis as an extraintestinal manifestation of Crohn's disease. Nat Clin Pract Nephrol 4:693-697. https://doi.org/10.1038/ncpneph0955

32. Dawson VJ, Dao D, Melanie Leu M, Egense A, Jinadu L, Malone L, Alexander J (2018) Tubulointerstitial nephritis and uveitis (TINU) with granulomatosis: a novel report of simultaneous TINU and sarcoidosis in a pediatric patient. J AAPOS 22:329 331. https://doi.org/10.1016/j.jaapos.2018.02.004

Publisher's note Springer Nature remains neutral with regard to jurisdictional claims in published maps and institutional affiliations. 